\title{
ВИРТУАЛЬНАЯ ОРГАНИЗАЦИЯ КАК НОВАЯ ОРГАНИЗАЦИОННАЯ ФОРМА УПРАВЛЕНИЯ ПРЕДПРИЯТИЕМ
}

\author{
(c) 2018 Хромов Иван Евгеньевич \\ кандидат экономических наук, старший научный сотрудник \\ Центральный экономико-математический институт РАН \\ 117418, г. Москва, Нахимовский проспект, 47 \\ E-mail:khromov_gaugn@mail.ru
}

Данная работа посвящена концепции виртуальной организации, как инструменту, позволяющему фирме сократить свои издержки и противостоять быстро меняющейся конъюнктуре рынка. Концепция виртуальной организации все ещё развивается, и пока даже не существует общего определения этого понятия, одобренного сообществом исследователей в этой области.

Ключевые слова: виртуальная организация, организационная структура, расширенное предприятие, головное предприятие, партнёрство, сокращение издержек, финансовое планирование, управление предприятием, проекты, закупки.

Тенденции развития современных рынков, такие как глобализация рынков, растущее значение качества товара, его цены и степени удовлетворения потребителей, повышение важности устойчивых отношений с потребителями (индивидуальными заказчиками), а также растущее значение степени применения новых информационных и коммуникационных технологий в большей степени повлияли на развитие новых организационных форм управления предприятием.

К основным характеристикам новых видов организационных структур предприятия можно отнести следующие: открытость; распределенная структура; гибкость; автономность; приоритет горизонтальных связей; ресурсосберегающие стратегии; обучаемость [7, с. 88].

Комбинации этих характеристик определяют классы предприятий нового типа:

Горизонтальное предприятие - характеризуется децентрализацией принятия решений, то есть имеет менее выраженную вертикаль власти. Принятие решений передается в автономные группы, состоящие из специалистов различных функциональных подразделений компании НИОКР, производство, маркетинг и сбыт. Такое предприятие образуется в основном вокруг конкретных процессов производства, и может оказаться успешнее вертикальной организации, например, при разработке и выводе на рынок нового продукта при ограниченном запасе времени.

Подвижное, или гибкое, предприятие представляет собой быстро изменяющуюся, гибкую

фирму, способную быстро реагировать на неожиданные изменения окружающей среды. Гибкое предприятие использует децентрализацию власти и горизонтальную производственную структуру для ускорения обмена информационными потоками между различными подразделениями компании и развития тесных доверительных отношений со своими клиентами и поставщиками.

Концепция интеллектуального предприятия утверждает, что интеллект является основным ресурсом в производстве и предоставлении услуг. Эта парадигма подчеркивает, что в современном мире ключом к расширению промышленности являются высокоинтеллектуальные системы. В качестве основных признаков интеллектуализации предприятия выделяют его быструю адаптацию к изменениям внешней и внутренней среды, диверсификацию стратегий деятельности, управление инновациями, структурные изменения, расширенное производство и управление интеллектуальным капиталом [1, c. 158].

Ресурсосберегающее предприятие предполагает оптимальное управление различными ресурсами (материальными, временными, человеческими), на основе методов:

- тотального управления качеством - максимальное качество для каждой производственной единицы

- совмещенной разработки - минимальное время цикла производства

- стратегии «точно в срок» (just-in-time) минимальные запасы. 
Расширенное предприятие - это совокупность всех организаций и частных лиц, принимающих участие в создании нового изделия. Оно представляет собой сеть самоорганизованных, слабо связанных между собой фирм, которые прямо или косвенно, официально или неофициально сотрудничают в области проектирования, разработки, производства и доставки продукта конечному потребителю. Фирмы в расширенном предприятии могут работать как независимо друг от друга, так и совместно [7, с. 48].

Головное предприятие, использующее услуги сторонних организаций, называют OEM-предприятием (OEM - Original Equipment Manufacturer). Головное предприятие может выполнять только конечную сборку товара, в то время как комплектующие изготавливаются различными субподрядчиками. Кроме головного предприятия и субподрядчиков в расширенное предприятие входят:

- поставщики различных материалов, стандартных деталей и узлов;

- заказчики, формирующие технические требования к изделию;

- потребители, тестирующие опытные образцы товара.

Виртуальная организация - это временное объединение независимых компаний - поставщиков, заказчиков и даже бывших конкурентов, связанных при помощи информационных технологий для обмена навыками, затратами и доступом к рынкам друг друга. У виртуальной организации зачастую нет ни центрального офиса, ни иерархии, ни вертикальной интегра- ции. Данное словосочетание часто используют для определения предприятий, действующих на виртуальных рынках и в сети Интернет, кроме того, виртуальные организации также обозначают как «сетевые предприятия», «виртуальные корпорации», «виртуальные предприятия».

Существует ещё множество определений виртуальной организации, например:

1. «Виртуальная организация - это добровольная временная форма кооперации нескольких, как правило, независимых партнеров (предприятий, институтов, отдельных лиц), обеспечивающая благодаря оптимизации системы производства благ большую выгоду клиентам» [2, c. 46].

2. «Под виртуальной организацией понимается сеть самостоятельных в правовом, но зависимых в экономическом отношении предприятий, которые на основе общих целей поставляют на рынок определенную услугу» [4, с. 93].

3. «Виртуальная организация создается путем отбора требующихся организационно-технологических ресурсов от различных предприятий и их интеграции в гибкую и динамическую структуру, приспособленную для скорейшего выпуска новой продукции и ее оперативной поставки на рынок» [8, с. 47].

4. «Виртуальная организация (промышленная, коммерческая, эксплуатационная и др.) это такая организация, которая создается из различных предприятий на контрактной основе, не имеет единой юридической организационной структуры, но обладает единой информационной структурой с целью создания и использова-

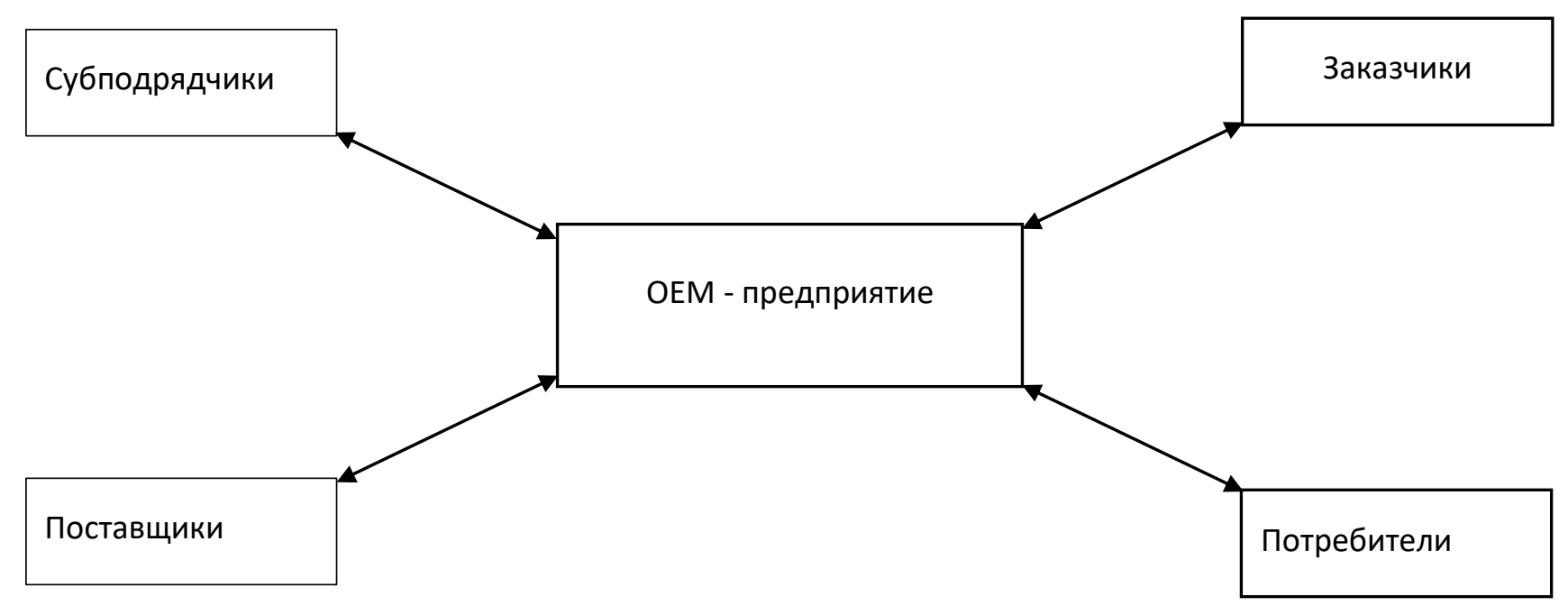

Рис 1. Участники расширенного предприятия [9, с. 28] 
ния компьютерной поддержки жизненного цикла конкретного изделия» [3, с. 15].

5. Виртуальная организация - сеть или свободная коалиция производства и административных услуг, объединенных для конкретной бизнес-задачи, которая распадается с достижением цели.

6. Виртуальная организация - это организация, использующее технологии для заключения широкого спектра временных союзов с целью захвата конкретных рыночных возможностей. В частности, виртуальная организация использует потенциал информационных технологий для облегчения взаимодействия через временные и географические границы.

Термин «виртуальная организация» используется для описания сети независимых фирм, которые объединяются, часто временно, для производства товара или услуги. Виртуальная организация часто ассоциируется с такими понятиями, как виртуальный офис, виртуальная команда и виртуальное руководство. Конечной целью виртуальной организации заключается в обеспечении инновационных, высококачественных продуктов и услуг по требованию заказчика.

Парадигма виртуальной организации получает все большее значение для производства как инструмент, позволяющий фирме противостоять быстро меняющейся конъюнктуре рынка. Для этого компании должны уметь быстро реагировать на требования заказчика и тесно сотрудничать со своими партнерами.

У.Дэвидоу и М. Мэлоун, утверждают, что идея виртуальной корпорации станет центром новой бизнес-революции. Их концепция объединяет различные характеристики, такие как поставки «точно-в-срок», гибкое производство, систему автоматизированного проектирования и ориентацию на индивидуального заказчика.

Целью виртуальной организации, как и любой другой организации, ориентированной на рынок, является получение максимальной прибыли, путем удовлетворения потребности потребителей в товарах и услугах. Однако, обычному предприятию для разработки и выведения товара на рынок необходимо привлечение значительных ресурсов. Виртуальная организация создает новый товар за счет привлечения новых партнеров, обладающих необходимыми знаниями, способностями и ресурсами. Так как большинство ресурсов привлекается со стороны, то организацией достигается резкое сокращение стартового капитала.

Такое партнерство является временным, то есть заключается на определенный срок, например, на срок выполнения заказа или до достижения определенного результата. Также это означает, что на различных этапах жизненного цикла товара возможно исключение старых партнеров и привлечение новых.

Если в сеть объединяется большое количество предприятий, особенно географически удаленных, то, очевидно, что им будет сложно согласовывать свои действия без оперативного доступа к информации. Следовательно, для решения подобных проблем предприятие должно иметь единую информационную систему, под которой понимается совокупность средств и методов поиска, обработки, передачи и хранения информации, необходимой для эффективного функционирования всей сети предприятий.

Так же, виртуальные организации, ориентируются на выполнение конкретных рыночных заказов и удовлетворение определенных потребностей конкретных потребителей, в то время как традиционные предприятия ориентированы на удовлетворение потребностей «усредненного» сегмента рынка.

В целом, к основным характеристикам виртуальной организации относят: открытую распределенную структуру; временный характер; гибкость; децентрализацию и приоритет горизонтальных связей; автономность, узкую специализацию и пространственную удаленность участников; высокий статус информационных средств обеспечения коллективной деятельности.

Несмотря на то, что формирование виртуальных организаций зачастую зависит от информационных технологий и степени их развития в целом, можно заметить, что так же есть факторы, существовавшие задолго до компьютерной эры. Например, в строительной отрасли группы независимых рабочих могли создавать организации для строительства домов и зданий. То же самое можно отнести и к киноиндустрии.

Выделяют четыре основных фактора, влияющих на возникновение и развитие виртуальных организаций:

- Скорость.

Если на рынке наиболее эффективными компаниями станут наиболее быстрые, а не наиболее приспособленные, то все компании будут стремиться к тому, чтобы как можно быстрее 
реагировать на любые изменения. Например, сегодня это можно наблюдать в сокращении жизненного цикла для всех видов деятельности в цепочке создания стоимости.

\section{- Cтоимость.}

Вторым фактором указывается снижение стоимости выхода на рынок, особенно в информационных и технически-ориентированных отраслях. В таких отраслях «даже небольшие стартапы с небольшим капиталом могут иметь огромное влияние на инновации, далеко за пределами границ своих возможностей».

\section{- Персонализация.}

Персонализация или кастомизация, становится все более возможной из-за автоматизированного производства.

Кроме того, организации сокращают затраты, сокращая свои производственные мощности, a кастомизация позволяет организациям производить индивидуальные продукты для более широких групп клиентов. Организации сейчас в большей мере руководствуются требованиями заказчика, а не внутренними потребностями.

\section{- Глобализация.}

Компании конкурируют не только со своими близко расположенными соперниками, но и с конкурентами по всему миру.

В совокупности, все эти факторы так же говорят о том, что иерархическая структура организации является не самым лучшим решением, не отвечает требованиям рынка, что говорит о жизнеспособности виртуальных организаций.

Кроме того, в основе всех этих факторов лежат информационные технологии, которые позволяют организации быстро собирать, интегрировать и анализировать большие объемы информации и распространять её по всему миру.

Вероятно, виртуальные организации все же могут существовать без информационно-коммуникационных технологий, как например в строительной индустрии. Тем не менее, без подобных технологий масштабы и области, в которых виртуальная организация осуществляет свою деятельность будет ограничена временем и географическим пространством.

Главным достоинством такой организационной формы, как виртуальная организация является возможность выбирать и использовать наилучшие ресурсы, знания, способности с наименьшими временными затратами. Кроме этого, к преимуществам данной формы можно отнести:
- Быструю реакцию и гибкую адаптацию к изменениям окружающей среды.

- Сокращение совокупных затрат, в том числе, например, на аренду рабочих помещений, их обслуживание, страхование.

- Рост конкурентных возможностей

- Гибкость

- Лучшая скорость реакции на требования рынка или клиентов

- Сокращение затрат

К недостаткам или, точнее, слабым местам такой организационной формы можно отнести:

- Высокие затраты, связанные с инвестициями в информационно-коммуникационными технологиями и последующие эксплуатационные расходы, включая обучение и техническое обслуживание.

- Правовые проблемы, связанные с тем, что границы между предприятиями внутри виртуальной организации становятся нечеткими. Это может привести к вопросам об авторском праве на продукцию между партнерами.

- Проблема доверия, как между партнерами, так и в целом по отношению к компании, которая может существовать только в виртуальном мире, но не в «реальном». Доверие и уважения являются одним из важных факторов существования успешной организации, причем это относится как к обмену знаниями и технологиями, так и к совместной работе, но из-за темпа создания виртуальной организации и географической разрозненности её партнеров могут возникнуть проблемы с доверием между ними. Из-за подобных проблем многие компании изначально отказываются от идей о кооперации.

- Разнородность членов предприятия вследствие происхождения из разных культур и географических регионов создает психологические барьеры между сотрудниками и клиентами. Кроме того, это усложняет рабочие контакты, в том числе из-за разницы во времени.

- Неясность в отношении членства в виртуальной организации, открытость сетей и неопределенность в планировании могут послужить причинами чрезмерного усложнения структуры организации.

- Отказ от классических долгосрочных контрактов не только вызывает увеличение транзакционных издержек, но и приводит к практическому отсутствию материальной и социальной поддержки членов организации [5, с. 94]. 


\section{Библиографический список}

1. Авдошин С.М., Тарасов В.Б. Синергетические организации в экономике XXI-го века // Бизнес-информатика. T. 17. 2006. C. $155-163$.

2. Вютрих Х.А., Филипn А.Ф. Виртуализация как возможный путь развития управления.// Проблемы теории и практики управления. 1999. № 5. С. 45-49.

3. Дмитров В.И. CALS, как основа проектирования виртуальных предприятий //Автоматизация проектирования. 1997. № 5. С. 14-17.

4. Зибер П. Управление сетью как ключевая компетенция предприятия. // Проблемы теории и практики управления. 2000. № 3. С. 92-96.

5. Райсс М. Границы «безграничных» предприятий: перспективы сетевых организаций // Проблемы теории и практики управления. 1997. № 1. С. 92-97.

6. Тарасов В.Б. «Новые стратегии реорганизации и автоматизации предприятий: на пути к интеллектуальным предприятиям», Новости искусственного интеллекта. 1996. № 4. С. 40-84.

7. Тарасов В.Б. Причины возникновения и особенности организации предприятия нового типа. // Проблемы теории и практики управления. 1998. № 1. С.87-90.

8. Тарасов В.Б. Предприятия XXI века: проблемы проектирования и управления. // Автоматизация проектирования. 1998 . № 4 . С. $45-52$.

9. Яблочников Е.И., Фомина Ю.Н., Саломатина А.А., Гусельников В. С., Методы управления жизненным циклом приборов и систем в расширенных предприятиях: учебное пособие. Санкт-Петербург. 2009. 149 с.

Поступила в редакцию 28.08.2018 